\title{
FORMAÇÃO DOCENTE E REPRODUÇÃO DE PRÁTICAS: Percepções de Egressos de um Curso de Formação de Professores para a Educação Profissional e Tecnológica
}

\author{
Cristiane Berenice Caraveta dos Santos ${ }^{1}$ \\ Claudemir de Quadros ${ }^{2}$
}

\begin{abstract}
RESUMO
Neste texto apresentam-se resultados de um trabalho realizado no âmbito do curso de Mestrado em Educação Profissional e Tecnológica, mantido pela Universidade Federal de Santa Maria, o qual consistiu em analisar as percepções de egressos do Programa Especial de Graduação para Formação de Professores para a Educação Profissional em relação a sua formação e atuação como professores. Buscou-se identificar e analisar as percepções de um grupo de egressos do período compreendido entre 2010 e 2015 que atuam ou atuaram na docência. Para a coleta de dados utilizou-se um questionário semiestruturado on-line e entrevistas. Foram enviados 952 questionários e realizadas 4 entrevistas. As informações foram selecionadas de acordo com os critérios de inclusão e exclusão estabelecidos para a pesquisa e submetidas à análise do conteúdo na perspectiva de Bardin (1977). Em termos gerais, os resultados demonstraram que os egressos indicam compreenderem as principais dimensões envolvidas na atuação docente e a necessidade de inovação e dinamismo nas aulas. Por outro lado, percebeu-se, pelos relatos, que suas práticas continuam a se pautar pela reprodução de procedimentos tradicionais, o que nos levou a pensar que, neste caso específico, não há uma relação, direta e necessária, entre a frequência em um curso de formação de professores e um melhor desempenho profissional docente.
\end{abstract}

Palavras-chave: Ensino profissionalizante. Políticas de formação docente. Percepções de egressos.

\section{TEACHING TRAINING AND REPRODUCTION OF PRACTICES: PERCEPTIONS OF FORMER STUDENTS OF A TRAINING COURSE OF TEACHERS FOR PROFESSIONAL AND TECHNOLOGICAL EDUCATION}

\section{ABSTRACT}

This text presents the results of a study carried out at the Master's Course in Professional and Technological Education, maintained by the Federal University of Santa Maria, which consisted of analyzing the perceptions of former students of the Special Program of Graduation for Teacher Training for the Professional Education in relation to their training and acting as teachers. The objective was to identify and analyze the perceptions of a group of graduates from the period between 2010 and 2015 who work or worked in teaching. For data collection a semi-structured online questionnaire and interviews were used. 952 questionnaires were sent and four interviews were conducted. The information was selected according to the inclusion and exclusion criteria established for the research and submitted to content analysis from the perspective of Bardin (1977). In general terms, the results showed that former students indicate that they understand the main dimensions involved in teaching and the need for innovation and dynamism in the classes. On the other hand, it was perceived from the reports that their practices continue to be guided by the reproduction of traditional procedures, which led us to think that, in this specific case, there is no direct and necessary relationship between the frequency of a teacher training course and a better teaching professional performance.

Keywords: Professionalizing education. Teacher training policies. Perceptions former students.

RECEBIDO EM: 22/10/2017

REVISÕES REQUERIDAS EM: 10/1/2018

ACEITO EM: 6/2/2018

\footnotetext{
${ }^{1}$ Bacharel em Administração, com Mestrado em Educação Profissional e Tecnológica pela Universidade Federal de Santa Maria/RS. criscaraveta@hotmail.com

${ }^{2}$ Licenciado em História, com Mestrado e Doutorado em Educação. Professor na Universidade Federal de Santa Maria/RS, atuando em cursos de formação de professores e no Programa de Pós-Graduação em Educação Profissional e Tecnológica. Editor da Regae - Revista de Gestão e Avaliação Educacional (https://periodicos.ufsm.br/ regae/index). Coordenador do Comitê de Ética em Pesquisa com Seres Humanos da UFSM http://lattes.cnpq.br/9506136012570087. Orcid: http://orcid.org/0000-0002-1204-0355. claudemirdequadros@gmail.com
} 
Neste texto apresentam-se os resultados de um trabalho realizado no âmbito do curso de Mestrado em Educação Profissional e Tecnológica, mantido pela Universidade Federal de Santa Maria/RS, que teve por objetivo analisar as percepções ${ }^{3}$ de um grupo de egressos do Programa Especial de Graduação para Formação de Professores para a Educação Profissional ${ }^{4}$ em relação à sua formação e atuação como professores. Em razão disso procurou-se traçar e identificar o seu perfil; buscar informações e dados acerca de como este grupo de egressos age no desenvolvimento da sua inserção e exercício profissional após a conclusão do curso e mapear as percepções de um grupo de egressos do período compreendido entre 2010 e 2015, que atuam ou atuaram na docência.

O trabalho apoiou-se na tentativa de indiciar as possíveis repercussões nas formas de atuação profissional docente desses novos professores que, a partir da formação inicial em âmbito de Bacharelado, mobilizaram-se com vistas a adentrar na docência. As preocupações gerais que orientam o texto podem ser expressas pelas seguintes perguntas: Quais foram as principais práticas adotadas pelos egressos que, de uma forma ou de outra, reverberam no seu dia a dia como docentes? Que elementos a frequência a um curso de formação de professores agregou ao exercício profissional da docência? Em outras palavras: o que mudou nas suas práticas, nos modos de fazer e proceder na sala de aula?

Para a coleta de dados utilizou-se de um questionário semiestruturado on-line, pela plataforma Google Forms, e entrevistas pelo aplicativo Whatsapp. Foram convidados a participar 952 egressos, dos quais 182 responderam ao questionário, e realizadas 4 entrevistas. As informações foram selecionadas de acordo com os critérios de inclusão e exclusão estabelecidos para a pesquisa e submetidas à análise de conteúdo na perspectiva de Bardin (1977).

\section{EXPANSÃO DA EDUCAÇÃO PROFISSIONAL E TECNOLÓGICA E FORMAÇÃO DE PROFESSORES}

O ensino profissionalizante esteve configurado de diferentes formas ao longo do tempo no Brasil. Em termos bem gerais, conforme o momento e contexto, prestou-se atenção à formação, capacitação e qualificação de profissionais para atuarem no mundo do trabalho, bem como ao desenvolvimento pessoal. Atualmente, ao menos em termos conceituais, espera-se que se constitua como algo integrado às diferentes formas de educação, trabalho, ciência e tecnologia, daí a expressão mais abrangente: Educação Profissional e Tecnológica - EPT.

A proeminência atual das discussões e pautas relacionadas à Educação Profissional e Tecnológica não se deve ao acaso, mas, entre outros aspectos, vincula-se à globalização e às mudanças no mundo do trabalho. Roger Dale (2004) e Abdeljalil Akkari (2011), por exemplo, apontam os impactos que esse movimento gerou nas políticas educacionais, em especial a partir das diretrizes propostas por diversas instituições in-

\footnotetext{
${ }^{3} \mathrm{Em}$ termos gerais, entende-se por percepção os processos pelos quais as pessoas tomam conhecimento de si, dos outros e do mundo a sua volta (MARCOLAN, 2009).

${ }^{4}$ Por meio deste curso busca-se formar e certificar professores, em nível superior, para atuar na educação profissional e tecnológica de nível médio (UFSM, 2015).
} 
ternacionais que têm, no seu horizonte de preocupação, a educação de um modo geral e, em especial, a educação profissional. Nesse sentido, a EPT foi envolvida num conjunto de reformas, as quais foram justificadas pelo fato de que, uma vez levadas a efeito, potencializariam melhorias nas condições econômicas, sociais e de inserção profissional de todos e de cada um. Os discursos feitos pela Organização para a Cooperação e Desenvolvimento Econômico - OCDE (2003) vão na mesma direção, ao apontarem que os países que investem pouco em educação não levam em conta os possíveis benefícios que podem ser gerados por ela na superação dos desafios sociais, assim como indicam que a educação pode promover o aprimoramento das habilidades, melhoria na condição social do indivíduo, maior longevidade, bem como uma possibilidade de atuação política ampliada.

Nesse contexto, em especial a partir das duas últimas duas décadas, o governo brasileiro instituiu programas que propiciaram a expansão da Educação Profissional e Tecnológica, com vistas a facilitar o acesso, incentivar a profissionalização, promover demanda por formação técnica para o ingresso no mundo do trabalho, bem como estimular novas qualificações. Promoveu-se, também, a criação de cursos de formação de professores para a atuação nesta modalidade de ensino.

Segundo dados do Ministério da Educação, investiu-se, na expansão da Educação Profissional e Tecnológica, mais de $\mathrm{R} \$ 3,3$ bilhões entre os anos de 2011 e 2014. No total são 562 escolas em atividade, 38 institutos federais que oferecem cursos de qualificação, Ensino Médio integrado, cursos superiores de Tecnologia e Licenciaturas. A partir destes dados é possível perceber a relevância do ensino profissionalizante no âmbito das políticas governamentais do tempo presente.

Pode-se destacar, ainda, a lei n. 11.892, 29 de dezembro de 2008, pela qual foi instituída a rede federal de educação profissional, científica e tecnológica, assim como foram criados os institutos federais. Em termos gerais, estes foram definidos como instituições de educação superior, básica e profissional, pluricurriculares e multicampi, especializados na oferta de Educação Profissional e Tecnológica nas diferentes modalidades de ensino, com base na conjugação de conhecimentos técnicos e tecnológicos com suas práticas pedagógicas.

Isso tem o potencial de requerer que o professor vinculado à EPT seja

um sujeito da reflexão e da pesquisa, aberto ao trabalho coletivo e à ação crítica e cooperativa, comprometido com sua atualização permanente na área de formação específica e pedagógica, que tem plena compreensão do mundo do trabalho e das redes de relações que envolvem as modalidades, níveis e instâncias educacionais, conhecimento da sua profissão, de suas técnicas, bases tecnológicas e valores do trabalho, bem como dos limites e possibilidades do trabalho docente que realiza e precisa realizar (MACHADO, 2008, p. 17).

Uma das manifestações da expansão da Educação Profissional e Tecnológica, assim como das pautas relacionadas à formação de professores para esta modalidade de ensino, foi a criação do Programa Especial de Graduação de Formação de Professores para Educação Profissional na Universidade Federal de Santa Maria - PEG/UFSM. Financiado por meio do plano de apoio a planos de reestruturação de expansão das universidades federais - Reuni - este curso funciona junto ao Centro de Educação e o argumen- 
to básico para a sua criação foi a necessidade, indicada pela LDB, de que a formação dos professores para atuar na Educação Básica devia ser feita em nível superior, em curso de Licenciatura.

São ofertadas 300 vagas anuais e para ter acesso ao curso o candidato deve ser portador do grau de bacharel. O objetivo geral do curso é promover a formação de professores, em nível superior, para atuar na modalidade de educação profissional no ensino técnico de nível médio. Ainda de acordo com o projeto pedagógico do curso (UFSM, 2015), procura-se promover a formação de professores com a capacidade de atuar em escolas de educação profissional, particulares e públicas, sindicatos, ONGs, cursos de formação inicial e continuada de trabalhadores ou cursos de ensino profissionalizante de nível médio, nos componentes curriculares vinculados à sua atuação formação técnico-profissional.

Em resumo, espera-se que os egressos do curso desenvolvam um perfil profissional amplo que envolve: capacidade de atuar com ética e compromisso; competência para utilizar novas metodologias, tecnologias, estratégias e materiais de apoio; comprometimento com a qualidade da aprendizagem dos estudantes; capacidade de utilizar aspectos da pesquisa como fundamentos pedagógicos em sua prática cotidiana; capacidade para promover a mediação e desenvolvimento de relações de cooperação entre a instituição educativa, a família e a comunidade; aptidão para se apropriar de saberes pedagógicos necessários à ação docente, tais como concepções epistemológicas que fundamentam a prática educativa (UFSM, 2015).

Apesar de a temática formação docente envolver um número expressivo de pesquisadores, o mesmo ocorre em menor grau em relação à formação docente para a educação profissional e tecnológica, que carece de estudos mais amplos, tal como argumentam Fartes e Santos (2011) e Gariglio e Burnier (2012). Cabe destacar que ensinar a ser professor envolve um conjunto de saberes que se articulam entre si. É uma tarefa que compreende algum grau de complexidade, como ressaltam Zabalza (2004), Nóvoa (2009) e Tardiff (2014), bem como requer o conhecimento do tema específico e das atividades que envolvem a docência, além da compreensão acerca da maneira como os estudantes se apropriam do conhecimento e dos modos de utilizar os recursos de ensino.

Nesse contexto convém destacar, em que pese a obviedade, que a profissão docente mudou ao longo do tempo, assim como não há uma única definição acerca do que seja ser professor. Nóvoa (1992) e Zabalza (2004), por exemplo, expressam esta situação ao se perguntarem como é que cada um se tornou o professor que é hoje? Ou o que nos faz ser bons professores, ensinar bem ou formar bons alunos? Assim, a profissão docente relaciona-se com um ofício profissional, na perspectiva proposta por Tardif e Lessard (2013):

Durante as últimas décadas, no contexto da generalização e de massificação da educação, e por extensão no quadro da burocratização dos sistemas educativos, o sindicalismo docente e as associações profissionais insistiram, com razão, para que o ensino fosse reconhecido como um ofício e os docentes, na qualidade de trabalhadores qualificados, fossem convenientemente tratados pelo seu empregador, nos planos material, social e simbólico (p. 255). 
Nóvoa (1992) agrega outro elemento importante ao considerar que, nos processos formativos, comparecem não apenas as definições e perspectivas conceituais da área, mas também o contexto no qual o professor se insere: cultura, crença, valores, expectativas e experiências pessoais.

Garcia (1999) destaca que a formação de professores é um processo sistemático e organizado, que envolve diversas estratégias, metodologias e modelos consolidados e no qual os professores aprendem e desenvolvem sua competência profissional, servindo tanto aos sujeitos que querem se tornar professores quanto aos que já atuam no ensino há algum tempo. Destaca-se, ainda, que a docência envolve conhecimento dos conteúdos e das metodologias, advertindo-se que, para exercê-la, convém possuir uma visão ampla da profissão.

Essas perspectivas são corroboradas por Machado (2008), para quem "na formação dos docentes para a educação profissional, é fundamental trabalhar diferentes formas de realização da transposição didática dos conteúdos específicos considerando a complexa diversidade apresentada por esta modalidade educacional e pelas dimensões econômicas, sociais e culturais das demandas dos contextos profissionais para os quais se formam os alunos."

\section{DESCRIÇÃO DE PROCEDIMENTOS E RESULTADOS}

A pesquisa realizou-se por meio de um estudo de caso, na perspectiva de Yin (2015), e para coleta de dados optou-se pela utilização de um questionário semi-estruturado, disponibilizado on-line pela plataforma Google Forms, e entrevistas com egressos, por meio do aplicativo Whatsapp. $O$ critério de inclusão para participar da pesquisa consistia em atuar ou ter atuado em sala de aula após a conclusão do curso. O critério de exclusão foi o seu contrário: não ter exercido o magistério, em nenhum momento, após a conclusão do curso.

Foram enviados questionários a 952 egressos do PEG/UFSM do período compreendido entre o segundo semestre de 2010 o segundo semestre de 2015. Destes, 182 questionários retornaram respondidos, foram organizados em planilhas e triados conforme os critérios preestabelecidos na pesquisa, totalizando 117 válidos. Para a entrevista foram contatados 4 egressos por meio do Facebook e Whatsapp. O roteiro da entrevista foi enviado por e-mail. As orientações relacionadas às questões foram enviadas por meio do Whatsapp, Facebook e também por e-mail.

Para a interpretação dos dados procurou-se pautar pela análise de conteúdo (BARDIN, 1997). A primeira fase incluiu revisão bibliográfica. Na segunda fase foram separados trechos, palavras, frases, repetidamente constantes nas manifestações dos egressos e, na terceira etapa, os termos e as expressões foram agrupados por similaridades em categorias e subcategorias. Uma vez realizada a categorização, buscou-se analisar aquelas que pudessem melhor expressar as percepções dos egressos, seja pelo que foi escrito, pelo que foi dito ou, até mesmo, pelo que não foi nem escrito e nem, tampouco, dito.

As categorias e subcategorias foram definidas nos seguintes termos:

a. Perfil do egresso: graduação, faixa etária, espaços de atuação.

b. Motivação para cursar o PEG/UFSM: incrementar o currículo, concursos, vontade de ser professor, demanda da instituição. 
c. Impactos produzidos pelo PEG/UFSM: nenhum ou pouco impacto, inserção no mercado de trabalho, reflexão, impactos positivos, melhora na atuação docente.

d. Estruturação das aulas.

e. Materiais e recursos utilizados: projetor de multimídia, quadro e giz/canetas, maquetes, filmes, livros e fotocópias.

f. Meios de comunicação: redes sociais, e-mail, Moodle, Whatsapp, portal acadêmico, secretaria, pessoalmente, todos os meios.

g. Metodologias utilizadas em aula: aula expositiva, resolução de problemas, tempestade de ideias, estudo de caso, seminários, estudo dirigido.

Finalmente, a quarta etapa consistiu na análise das percepções que os respondentes do questionário e da entrevista expressaram quanto à sua atuação profissional docente.

Em termos de Perfil deste grupo de egressos observou-se que a maioria é oriunda de cursos da área das Ciências Rurais, seguidas das Exatas, Humanas e Biológicas. A faixa etária predominante compreende pessoas entre entre 30 e 35 anos. Uma parcela desses egressos já atuava na docência quando buscou o curso. A maioria atuou ou atua em escolas mantidas pelos governos e $25 \%$ dos respondentes optaram por seguir outra carreira não vinculada à docência.

Entre os motivos mas frequentemente elencados para acessar o curso estão: a vontade de se tornar professor, expressa por de $40 \%$ dos respondentes; incrementar o currículo e a aprovação em concurso público, com um percentual de $22 \%$ cada; cursar o programa por exigência da instituição de vínculo (5\%).

No quesito sentir-se habilitado ao exercício da profissão a maioria, $77 \%$ dos respondentes, consideram-se seguros para atuar em sala de aula, enquanto que os outros $33 \%$ consideram-se parcialmente aptos. Cabe lembrar que a maioria não havia tido contato com o trabalho docente antes do PEG/UFSM.

Na perspectiva de Huberman (1992), a entrada na docência é uma fase de descobertas, em que o professor passa por inúmeras situações, algumas inesperadas, dentro e fora da sala de aula. Nessa etapa há um amadurecimento da relação professor e aluno, quando acordos são propostos, negociados. Isso integra os processos de ensino, momento em que as expectativas e perspectivas são confirmadas ou frustradas: essa ansiedade pode ser percebida nos respondentes que afirmaram não se sentirem seguros para atuar na docência.

Segundo Tardif (2014, p. 261), "esses primeiros anos de prática profissional são decisivos". Nesse período os conhecimentos vivenciados no curso de formação são postos em prática, ou não, são validados ou apenas compõem mais um conjunto de saberes abordados e arquivados. O relacionamento com os colegas, com a instituição, a adaptação a diferentes situações e a rotina de trabalho ditam o tom das decisões tomadas por esses novos professores, compondo uma experiência profissional.

A categoria Impactos produzidos pelo PEG/UFSM refere-se a concepções que o curso de formação de professores pode ter produzido nesses novos docentes e como isso reverbera em suas manifestações e práticas. Pode-se notar que há inúmeras per- 
cepções elencadas, as quais culminaram na elaboração de subcategorias: nenhum ou pouco impacto, inserção no mercado de trabalho, reflexão, impactos positivos e melhora na atuação docente.

A subcategoria denominada Pouco ou nenhum impacto reflete a frustração de alguns dos egressos com o curso: "Para mim não teve muito impacto", "Nenhum. Curso muito fraco", "Poucos. Infelizmente não acrescentou muito em termos de novos métodos de ensino para a docência em âmbito superior. Esperava mais do curso".

Na subcategoria Inserção no mercado de trabalho 16 egressos destacaram que o curso possibilitou uma porta de entrada ao mundo do trabalho. Convém lembrar que, devido à expansão da EPT, que incluiu ampliação da estrutura física e a criação de novos cursos técnicos, a demanda por professores certificados foi o impulso para a criação de cursos e programas como o PEG/UFSM.

Reflexão, termo bastante citado pelos egressos, intitula a terceira subcategoria, em que se agrupou um total de 20 respondentes. Neste aspecto pode-se considerar, com Tardif (2014) que, se por um lado os professores são profissionais limitados em vários aspectos, o que acarreta comportamentos não planejados em sala de aula, a possibilidade de pensar e refletir sobre as ações efetivadas pode promover melhoraria nas práticas docentes.

Analisar o modo como se exerce a docência e o porquê se adere a diferentes práticas faz parte do autoconhecimento como profissional. Nestes termos, a maior parte dos egressos contemplou o curso sob aspecto positivo e isso se reflete nas duas últimas subcategorias: Impactos positivos e Melhora na atuação docente, em que os respondentes externaram pontos acerca de sua prática e de seus relacionamentos com o ambiente escolar. Pela subcategoria Impactos positivos pode-se entender que os egressos, mesmo com algumas ressalvas, conseguiram desenvolver aspectos relevantes para sua formação, mesmo considerando que o processo deve ser contínuo. Na subcategoria Melhora na atuação docente salientaram-se em quais aspectos os egressos elencam melhoria no trabalho docente, tais como: organização de práticas pedagógicas, organização curricular, ampliação dos conhecimentos sobre a área da educação, da psicologia educacional e das instituições de ensino.

Na categoria Estruturação das aulas a maior parte dos egressos argumentou que diversifica seus métodos de ensino ou utiliza diferentes tipos de recursos; mescla aulas práticas e teóricas, aliando recursos tecnológicos; segue o conteúdo programático, aborda por meio de problemas, discussões e exercícios; retoma o conteúdo anterior e disserta acerca do tema, aplicando prova quando necessário. A maioria das respostas descreve o modo como esses egressos agem no seu dia a dia em sala de aula. Observam-se diferentes perspectivas, tais como: utilização da metodologias e ferramentas conhecidas durante o curso; estruturação das aulas partindo do conhecimento e da evolução dos alunos; estruturação de ações a partir da construção de um plano de aula. Alguns dos egressos declaram, ou deixam transparecer, por meio de suas respostas, desconhecerem os processos de estruturação de aula:

Egresso n. 35: Não uso métodos aprendidos no PEG/UFSM.

Egresso n. 46: Boa. 
Egresso n. 50: O PEG/UFSM não contribuiu para a estruturação das aulas, apenas colaborou sobre o pensar em ser docente.

Egresso n. 62: Não aprendi sobre isso no PEG/UFSM.

A quinta categoria, intitulada Materiais e recursos utilizados, refere-se aos meios usados pelos egressos nas suas aulas. Pode-se perceber que o projetor multimídia é o recurso preferido por $70 \%$ dos respondentes, seguido de quadro, giz e canetas (12\%). Os demais dizem utilizarem-se de livros, fotocópias, filmes, músicas ou outros recursos.

Figura 1 - Recursos mais utilizados nas práticas docentes

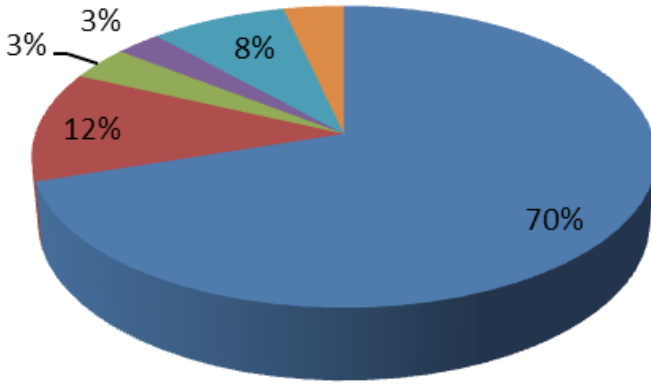

- Projetor de multimída
@ Quadro, giz, canetas
- Filmes e músicas
- Livros, fotocópias
- Todos
- Outros

Fonte: SANTOS, 2017.

A comunicação se constitui em um fator relevante entre professor e aluno. Em razão disso, coube o questionamento acerca de quais meios são utilizados na comunicação com os discentes. As formas mais citadas foram: e-mail, com $40 \%$ de adesão, e Moodle, com 29\% de adesão.

A categoria intitulada Metodologias utilizadas em aula aborda quais as metodologias são mobilizadas, para os processos de ensino e apredizagem, com mais frequência pelos egressos. Destaque-se que uma das competências proposta no projeto pedagógico do curso é que haja o desenvolvimento da capacidade de utilização de novas metodologias, tecnologias, estratégias e materiais de apoio (UFSM, 2015). Para tanto, no questionário, elencou-se uma tipologia de métodos possíveis, apresentada no Quadro 1 , com espaço para citação de alguma outra que, porventura, fosse utilizada.

Quadro 1 - Tipologia das metodologias apresentadas no questionário

\begin{tabular}{|l|l|}
\hline \multicolumn{1}{|c|}{ Metodologia } & \multicolumn{1}{c|}{ Definição } \\
\hline Aula expositiva & $\begin{array}{l}\text { É uma exposição do conteúdo, com a participação ativa ou não } \\
\text { dos alunos, partindo ou não do seu conhecimento prévio. Pode } \\
\text { favorecer a análise crítica, esperando como resultado a produção } \\
\text { de novos conhecimentos. }\end{array}$ \\
\hline Resolução de problemas & $\begin{array}{l}\text { Consiste no enfrentamento de uma situação nova, exigindo reflexão, } \\
\text { criatividade e criticidade para lidar com dados expostos na descrição } \\
\text { do problema. Demanda aplicação de leis e princípios que podem ou } \\
\text { não estar expressos. }\end{array}$ \\
\hline Estudo de caso & $\begin{array}{l}\text { Embasa-se na análise minuciosa e objetiva de uma situação real que } \\
\text { necessita ser investigada. }\end{array}$ \\
\hline
\end{tabular}




\begin{tabular}{|l|l|}
\hline Tempestade de ideias & $\begin{array}{l}\text { Consiste na possibilidade de estimular a geração de novas } \\
\text { ideias, espontaneamente, sem sinalização do certo e errado no } \\
\text { primeiro momento, podendo haver a solicitação de explicações } \\
\text { posteriormente. }\end{array}$ \\
\hline Estudo dirigido & $\begin{array}{l}\text { Ato de estudar sob a orientação e diretiva do professor, com vistas a } \\
\text { sanar dificuldades específicas, tendo claro o que é, para que e como } \\
\text { é preparada a sessão de estudo. }\end{array}$ \\
\hline Seminário & $\begin{array}{l}\text { Consiste num espaço em que um grupo discute ou debate temas ou } \\
\text { problemas que são postos em discussão. }\end{array}$ \\
\hline
\end{tabular}

Fonte: Adaptado de ANASTASIOU; ALVES, 2004, p. 78-99.

Poucas foram as metodologias diferentes das mencionadas nesta lista que os respondentes citaram, não chegando a constituir $1 \%$ do total: esse é um aspecto que chama a atenção, na medida em que evidencia a relação entre aquilo que os professores dizem fazer e aquilo que fazem. Note-se, ainda, que o tipo de metodologia escolhida revela o modo como os professores abordam seus conteúdos e como entendem que seus alunos assimilarão.

Mediante a observação da Figura 2, pode-se perceber que aula expositiva consiste na metodologia mais utilizada. Convém destacar que existem diferentes fatores que podem influenciar o modo como o professor ensina, tais como o estilo de vida dentro e fora da escola, as suas identidades e culturas (GOODSON, 1992), assim com há inúmeros fatores que interferem no aprendizado dos alunos, tais como motivação, capacidade, tempo dedicado ao estudo, estratégias de aprendizagem que independem dos professores (ZABALZA, 2004). Há, no entanto, indicações (NÓVOA, 2007), por exemplo, na direção de que é preciso modificar, atualizar as práticas docentes, fazer uma abordagem mais interessante dos conteúdos, no intuito de despertar o interesse em aprender. Afinal,

ensinar não é só mostrar, explicar, argumentar, etc., os conteúdos. Quando falamos sobre ensino, aludimos também ao processo de aprendizagem: ensinar é administrar o processo completo de ensino e aprendizagem que se desenvolve em um contexto determinado, sobre certos conteúdos específicos, junto a um grupo de alunos com características particulares (ZABALZA, 2004, p. 123).

Figura 2 - Metodologias mais utilizadas nas práticas docentes

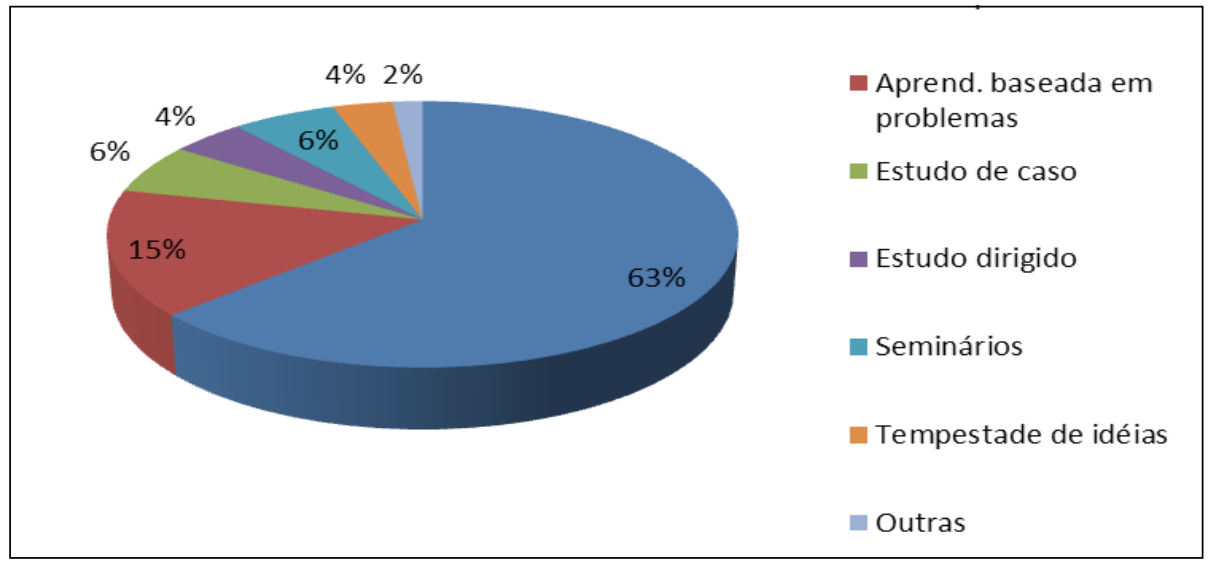

Fonte: SANTOS, 2017. 
Pelas respostas sintetizadas na Figura 2 percebe-se que as metodologias mais utilizadas seguem a seguinte ordem: aula expositiva, com $63 \%$ de adesão; resolução de problemas (15\%); estudo de caso e seminários, com 6\% de adesão; estudo dirigido e tempestade de ideias, com $4 \%$ de adesão. Assim, tem-se que os dados podem indiciar a presença da reprodução de práticas costumeiras ou, dito de outro modo, que a frequência a um curso não produz, necessariamente, comportamentos diferentes daqueles aos quais se está habituado ${ }^{5}$.

Outra etapa do trabalho envolveu a realização de entrevistas, as quais se constituíram num aspecto importante da pesquisa ao fornecer percepções mais refinadas acerca do curso, da relação entre colegas e professores, assim como em relação às experiências profissionais. Dos cinco convidados a participar, quatro responderam às questões:

a. Entrevistado A: Graduação em Engenharia Florestal, Mestrado em Silvicultura e Proteção Ambiental, Doutorado em Silvicultura.

b. Entrevistado B: Graduação e Mestrado em Engenharia Florestal, Doutorado em Engenharia Florestal.

c. Entrevistado C: Graduação em Direito e Ciências Contábeis, Mestrado em Direito e Educação, Doutorado em Engenharia de Produção.

d. Entrevistado D: Graduação e Mestrado em Agronomia, Doutorado em Agronomia.

Os questionamentos abrangeram: motivação para cursar o programa, recordações do curso, percepção de mudanças na atuação, relevância do programa na formação do egresso, opinião acerca da formação recebida e contribuições para melhoria do programa.

No que se refere à motivação para frequência ao curso as respostas convergem para questões relacionadas com aprender ou ter habilitação para a docência, necessidade de conhecimento do âmbito da didática, busca de qualificação, concorrer à vaga em concursos. Entre os elementos apontados pelos egressos destacam-se o desenvolvimento de confiança para estar diante dos alunos, o aumento da concentração, a capacidade de improvisação e a capacidade de diversificação ou de tornar a aula mais atrativa, saindo do padrão das aulas exclusivamente técnicas.

Entrevistado A: "Minha motivação foi a necessidade de me qualificar, para poder concorrer a vagas nos institutos federais. Também foi para aprender técnicas de como melhorar minhas futuras aulas".

Entrevistado B: "A minha motivação para cursar o PEG foi justamente que, no Bacharelado, não aprendi nada em relação a dar aulas, somente às matérias técnicas. Então eu pensei: vou ir para o PEG aprender a dar aulas, ser licenciada".

\footnotetext{
${ }^{5}$ A repetição de modelos talvez possa remeter à perspectiva de Tardif (2014), acerca das pré-concepções do que seja ensinar: "Ao longo de sua história de vida pessoal e escolar, supõe-se que o futuro professor interioriza um certo número de conhecimentos, de competências, de crenças, de valores, etc., os quais estruturam sua personalidade e suas relações com os outros [...] e são reatualizados e reutilizados, de maneira não reflexiva, mas com grande convicção na prática do seu ofício" (p. 72). Ou seja, há indícios de que cada professor traz consigo modelos, os quais reproduz nas suas atividades, no geral de forma não refletida.
} 
Entrevistado C: "Eu acho que é muito importante em função da necessidade da tu ter uma didática. Minha motivação pra cursar o PEG foi querer ser professora, e querer mostrar de forma que eu possa ajudar esses alunos a melhorar".

Entrevistado D: "Ter habilitação em mãos".

Os entrevistados destacam que passaram a adotar novos procedimentos, planejando a aula antecipadamente, prevenindo percalços e dificuldades, algo que não entendiam como necessário.

Entrevistado A: "Hoje eu penso diferente, eu planejo melhor as aulas, sempre tenho plano A, plano B".

Entrevistado B: "Agora sou bem mais flexível, eu tenho um panorama geral na aula na minha cabeça, tenho plano $A, B, C$, caso não dê certo, levo alternativas pra gente poder trabalhar em aula".

Entrevistado C: "Eu consigo me pôr no lugar do aluno que tá sentado".

Entrevistado D: “Antes eu não iria preparar uma aula com plano de aula tão estruturado".

Quanto às metodologias e aos recursos utilizados nas aulas, ressaltam a importância do projetor de multimídia e dos slides, porém um dos aspectos mais lembrados são as afetividades desenvolvidas no decorrer do curso:

Entrevistado A: E o que mais me recordo são as amizades.

Entrevista B: "Recordo-me de muitas coisas do curso, de vocês, das amizades, dos professores queridos e dos muitos trabalhos que a gente tem que fazer".

Entrevistado C: "O que mais me recordo do curso é a gentileza e elegância dos professores que eu tive".

Entrevistado D: "O que mais recordo do curso é dos colegas, das amizades que ficaram, das pessoas legais que nós tínhamos na turma, alguns professores".

Questionados sobre como deveria ser a formação do professor para a educação profissional, os respondentes afirmaram que o curso fornece elementos que possibilitam um embasamento ao professor, mas enfatizam a necessidade de maior relação entre aspectos teóricos e práticos. Pelo conteúdo das entrevistas notou-se a percepção da relevância do curso na formação profissional, ao expressarem que ele os ajudou a entender sobre planejamento, organização, improvisação, novas possibilidades e maior desenvoltura nas aulas.

\section{CONSIDERAÇÕES FINAIS}

Em termos gerais, os resultados da pesquisa apontaram que transitar da posição de bacharel para professor de Educação Profissional e Tecnológica implica lidar com elementos antes desconhecidos ou pouco alinhados com os conhecimentos desenvolvidos no decorrer da formação inicial. 
Em alguns egressos percebe-se que estar diante de situações como uma sala de aula, tendo de demonstrar habilidade para administrar o tempo e a turma, bem como abordar, em termos de ensino, aprendizagem e avaliação, os conhecimentos técnicos específicos de modo claro e preciso, causa inquietações e insegurança. Por outro lado, pode-se afirmar que as trocas de experiências vivenciadas ao longo do curso, nos estágios, em atividades coletivas e a ambientação proporcionada pelas atividades promovidas no curso fizeram com que os egressos desenvolvessem algum grau de confiança, assim como conseguissem pensar acerca da docência. Pode-se concluir que se evidenciou a importância do relacionamento construído com os professores e os colegas e que o intercâmbio entre pessoas de diferentes áreas parece ter se constituído em elemento relevante para a formação docente, na percepção dos egressos.

Embora a maioria dos egressos que participaram do estudo tenham apontado a necessidade ou conveniência da utilização de outras metodologias de ensino, o que foi explicitado, de modo recorrente, tanto nos questionários quanto nas entrevistas, é que suas práticas cotidianas permanecem próximas das já conhecidas ou que a introdução de outras metodologias ou tecnologias tende a ficar restrita às intenções e, mesmo quando acontecem, ocorrem de forma pontual. É importante lembrar, entretanto, que, mesmo adotando os modelos usuais, os egressos percebem que estão num estágio qualitativamente melhor do qual se encontravam antes de iniciar o curso.

No que diz respeito à comunicação nota-se que, da mesma forma como ocorre com a introdução a novas metodologias ou tecnologias, poucos egressos se utilizam de outras formas de comunicação, como as redes sociais, por exemplo. No geral adota-se e-mails ou os portais institucionais, como o Moodle.

Envolver-se mais com a prática docente e familiarizar-se com o futuro ambiente de trabalho, entender os mecanismos, as rotinas do ensino profissionalizanete, assim como dialogar com os alunos, escutar suas necessidades, entender suas dificuldades em relação ao aprendizado e captar suas expectativas foram preocupações ou inquietações manifestadas de modo recorrente pelos egressos.

Mesmo tendo transitado pelos estágios supervisionados, que abrangem atividades de visitação às instituições escolares, observações em sala de aula e inserção profissional, os egressos consideram que não houve tempo necessário ou suficiente para se aprofundarem na realidade escolar. Essa situação foi sentida de modo mais explícito quando confrontados com situações práticas, ou seja, aprende-se, também, e sobretudo, no decorrer da inserção profissional após a conclusão do curso, às vezes de modo intuitivo, às vezes por erros e acertos, às vezes pelos saberes das experiências, às vezes pelas referências de ex-professores.

Assim, no caso específico deste curso, os resultados demonstraram que, se por um lado, os egressos demonstram compreender as dimensões envolvidas na atuação docente e a necessidade de inovação e dinamismo nas aulas, por outro lado percebe-se que suas práticas pautam-se pela reprodução de procedimentos tradicionais: aula expositiva com a utilização do projetor de multimídia. Ou seja, não há uma relação, direta e necessária, entre ter frequentado um curso e mudar as formas de atuação em sala de aula. 
Certamente que, pelo caráter de formação inicial do curso, nem todas as intenções propostas ou expectativas prescristas no projeto pedagógico podem ser alcançadas, afinal a formação do professor segue um longo caminho no decorrer da carreira profissional, assim como compreender a complexidade dos saberes que envolvem o trabalho docente, aliando-os aos pressupostos da educação profissional e tecnológica, não se constitui uma tarefa simples. Envolve capacidade de lidar com diferentes instâncias sociais: governos, políticas públicas educacionais, instituições de ensino, professores, dirigentes, estudantes, itinerários formativos, assim como há uma larga distância entre efeitos prescritos, almejados e alcançados no decorrer dos processos formativos. Isso tem relação, ainda, com perspectivas individuais dos estudantes, contextos de inserção, atuação e práticas dos professores formadores, assim como com as dimensões éticas e profissionais que estão ao alcance do entendimento de cada um.

Por fim, pode-se destacar a produtividade destes dados para a avaliação institucional ou para se pensar e problematizar aspectos relacionados com a avaliação dos formadores, repercussões de sua atuação nas práticas profissionais, desenvolvimento curricular ou avaliação da estruturação e funcionamento dos projetos pedagógicos dos cursos. Enfim, há um campo aberto para estudos vinculados com a avaliação educacional.

\section{REFERÊNCIAS}

AKKARI, Abdeljalil. Internacionalização das políticas educacionais: transformações e desafios. Petrópolis: Vozes, 2011.

ANASTASIOU, Léa das Graças; ALVES, Leonir Pessate (org.). Estratégias de ensinagem. In: ANASTASIOU, Léa das Graças; ALVES, Leonir Pessate. Processos de ensinagem na universidade: pressupostos para estratégias de trabalho em aula. Joinvile: Univalle, 2004, p. 74-107.

BARDIN, Laurence. Análise de conteúdo. Lisboa: Edições 70, 1977.

CARVALHO, Olgamir Francisco de; SOUZA, Francisco Heitor de Magalhães. Formação do docente da educação profissional e tecnológica no Brasil: um diálogo com as faculdades de educação e o curso de pedagogia. Educ. Soc., Campinas, v. 35, n. 128, p. 629-982, 2014.

DALE, Roger. Globalização e educação: demonstrando a existência de uma cultura educacional mundial comum ou localizando uma agenda globalmente estruturada para a educação? Educ. Soc., Campinas, v. 25, n. 87, p. 423-460, 2004.

FARTES, Vera; SANTOS; Adriana Q. Oliveira. Saberes, identidades, autonomia na cultura docente da Educação Profissional tecnológica. Cadernos de Pesquisa, v. 41, n. 146, p. 376-401, 2011.

GARCIA, Carlos Marcelo. Formação de professores: para uma mudança educativa. Porto: Editora Porto, 1999.

GARIGLIO, José Ângelo; BURNIER, Suzana. Saberes da docência na educação profissional: um estudo sobre o olhar dos professores. Educação em Revista, Belo Horizonte, v. 28, n. 1, p. 211-236, 2012.

GOODSON, Ivor. Dar voz ao professor: as histórias de vida dos professores e o seu desenvolvimento profissional. In: NÓVOA, António (org.). Vida de professores. Lisboa: Porto, 1992. p. 63-73.

HUBERMAN, Michael. O ciclo de vida profissional dos professores. In: NÓVOA. António (org.). Vida de professores. Lisboa: Porto, 1992, p. 31-61.

MACHADO, Lucília Regina de Souza. Diferenciais inovadores na formação de professores para a educação profissional. Revista Brasileira da Educação Profissional e Tecnológica, Brasília: MEC, v. 1, n. 1, p. 8-22, 2008.

MARCOLAN, Angela Focking. A influência de um jogo de empresas na percepção da necessidade de desenvolvimento de competências em integrantes de empresas familiares. 2009. 105f. Dissertação (Mestrado em Engenharia de Produção) - Universidade Federal de Santa Maria, UFSM, Santa Maria, 2009.

NóVOA, António (org.). Os professores e as histórias de sua vida. In: NÓVOA, António (org.). Vida de professores. Lisboa: Porto, 1992. p. 11-30. 
NÓVOA, António. Desafios do trabalho do professor no mundo contemporâneo. São Paulo: Sinpro, 2007. NÓVOA, António. Professores: imagens do futuro presente. Lisboa: Educa, 2009.

OCDE. Organização para a Cooperação e Desenvolvimento Econômico. Síntese das análises das políticas educacionais. 2003. Disponível em: https://www.oecd.org/edu/school/20946947.pdf. Acesso em: 6 mar. 2016.

SANTOS, Cristiane Berenice Caraveta dos. Do bacharelado à docência: percepções dos egressos do PEG/ UFSM quanto a atuação profissional docente. 2017. 74f. Dissertação (Mestrado em Educação Profissional e Tecnológica) - Universidade Federal de Santa Maria, UFSM, Programa de Pós-Graduação em Educação Profissional e Tecnológica, Santa maria, 2017.

TARDIF, Maurice; LESSARD, Claude (org.). As transformações atuais do ensino: três cenários possíveis na evolução da profissão de professor? In: TARDIF, Maurice; LESSARD, Claude. O ofício de ser professor: história, perspectivas e desafios internacionais. Petrópolis: Vozes, 2013. p. 255-277.

TARDIF, Maurice. Saberes docentes e formação profissional. Petrópolis: Vozes, 2014.

UFSM. Universidade Federal de Santa Maria. Projeto pedagógico de curso: PEG 2009-2015. Santa Maria: UFSM, 2015. Disponível em: http://w3.ufsm.br/prograd/index.php/documentos/ppcs-projetos-pedegogicos. Acesso em: 3 mar. 2016.

YIN, Robert. Estudo de caso: planejamento e métodos. Porto Alegre: Bookman, 2015.

ZABALZA, Miguel A. O ensino universitário: seu cenário, seus protagonistas. Porto Alegre: Artmed, 2004. 